\title{
El cuidado de la experiencia del crecer en el dispositivo clínico
}

\author{
Laura Isabel Franco Amaris* \\ Medellín, Colombia
}

\begin{abstract}
Este texto habla acerca de los jóvenes universitarios que van a consulta psicológica para resolver cuestionamientos sobre sí mismos y sobre otros aspectos fundamentales de su psiquismo y su realidad. El dispositivo clínico se convierte en un escenario que facilita la elaboración de dichos cuestionamientos. El psicólogo, por su parte, hace las veces de cuidador, valiéndose de una actitud de negociación, receptividad, comprensión, desnudez y espontaneidad; al igual que de artificios técnicos como el holding, el juego y la creatividad, para posibilitar que los jóvenes elaboren su experiencia de estar creciendo.
\end{abstract}

Palabras clave: jóvenes, crecimiento, cuidado, dispositivo clínico, psicólogo.

This paper talks about young university students who go to psychological consultation in order to resolve their questions about themselves, and others that are fundamental to their psyche and their reality. The clinical device becomes the stage that facilitates the elaboration of such questionings. The psychologist, meanwhile, acts as a caregiver, using an attitude of negotiation, receptivity, understanding, nudity and spontaneity; as well, using some technical artifices such as holding, play and creativity, to enable young people to elaborate their experience of being growing.

Key Words: young, growth, care, clinical device, psychologist.

English Title: The care of the growing experience in the clinical device

\section{Cita bibliográfica / Reference citation:}

Franco Amaris, L.I. (2018). El cuidado de la experiencia del crecer en el dispositivo clínico. Clínica e Investigación Relacional, 12 (2): 336-342. [ISSN 1988-2939] [Recuperado de www.ceir.info] DOI: $10.21110 / 19882939.2018 .120207$

\footnotetext{
* Psicóloga de la Universidad Católica Luis Amigó (Funlam). Medellín, Colombia. Correo electrónico: laurafrancoam@gmail.com
} 
La naturalidad y sinceridad del comportamiento (Groddeck, Thompson) es la actitud más oportuna y beneficiosa en la situación analítica; el paciente se dará cuenta enseguida si nos aferramos a una postura dictada por la teoría, y en lugar de decírnoslo (o decírselo) aprovechará nuestra manera o unilateralidad técnica para llevarnos al absurdo.

Ferenczi, 2008

Da la sensación de que el título de este texto dice muchas cosas; por esto, a lo largo del mismo trataré de elaborar dicho título a la luz de la pregunta que lo orienta. Este escrito es el resultado del trabajo clínico con jóvenes que se encuentran en un contexto universitario y que acceden al servicio de asesoría usualmente por voluntad propia. Por ello, he venido preguntándome cómo se acompaña a un sujeto que consulta por causa de situaciones enigmáticas asociadas al hecho de estar creciendo.

Pero... ¿por qué «situaciones enigmáticas»? El Diccionario de la Real Academia define 'enigma' como una «realidad, suceso o comportamiento que no se alcanza a comprender, o que difícilmente puede entenderse o interpretarse». Puede decirse, con palabras más concretas, que las situaciones enigmáticas son aquellas en que el sujeto se hace preguntas.

En este orden de ideas, ¿qué tipo de preguntas suele hacerse un joven universitario?, ¿con qué preguntas llega al consultorio psicológico de su universidad? Empecemos a considerar el crecimiento y el tiempo psíquico que implica ser joven; y cuando hablo de joven me adhiero a la lógica del Estatuto de Ciudadanía Juvenil (Congreso de Colombia, 2013), en el cual se concibe a los sujetos entre los 14 y los 28 años como jóvenes, recogiendo en esta categoría un fragmento de la adolescencia. Sin embargo, en el dispositivo clínico lo que priman son las lógicas psíquicas propias de ser joven, las cuales no necesariamente se circunscriben a la edad.

Ahora bien, el dispositivo clínico es un espacio que permite que el sujeto se hable a sí mismo, escenifique su historia, se haga preguntas $y$, en el mejor de los casos, encuentre respuestas. De ahí que cabe la pregunta: ¿qué necesita el sujeto para sentir que puede escenificar, preguntarse, responderse o hablarse en este espacio? Y, siendo más específicos ¿qué necesita un joven universitario para permitirse esto? Antes de intentar responder estos cuestionamientos, pensemos en los tiempos psíquicos de un joven.

Espinosa (2010) propone que la adolescencia es un proceso de transición, en el cual acontecen unas tareas psíquicas motivadas por los cambios biológicos y sociales. Estas tareas psíquicas obedecen a tres preguntas: ¿quién es?, ¿a qué se dedica?, ¿a quién amar?, las cuales permiten que el sujeto reelabore su posición subjetiva. El autor nombra tres tareas psíquicas fundamentales en esta fase evolutiva: el alejamiento de la representación que un adolescente 
interiorizó en la infancia sobre sus padres, el estar en ambientes relacionales diferentes a la familia y la reconfiguración del sí mismo.

Grosso modo, cuando se habla del alejamiento de la imago parental se hace alusión a la reelaboración del complejo de Edipo, a una nueva elección y al desasimiento de la representación de los padres. De ahí que algunos autores posfreudianos llamen a este momento «segundo proceso de individuación» y para hacerlo los jóvenes se separan de su núcleo familiar (ibíd.). En algunos casos, esta tarea implica un monto considerable de agresión, dependiendo del lugar que ocupa la familia en la narración de cada joven.

Estar en ambientes relacionales diferentes a la familia, permite que se pongan a prueba los recursos psíquicos de los jóvenes, por medio del establecimiento de nuevas relaciones que sustituyan lo familiar; de ahí que la función que cumplen los amigos sea primordial, pues son quienes psíquicamente hacen las veces de articuladores, y matizan la oposición entre ambientes familiares y no familiares. A su vez, estar afuera pone a prueba la capacidad para estar solo, lo cual es un indicador del desarrollo emocional que posibilita que un sujeto se sienta suficientemente dispuesto para la vida (ibíd.).

Responder a la pregunta por quién se es tiene alcances edificantes, pues es precisamente un proceso de reordenamiento psíquico, en tanto hay una remodelación tópica que hace referencia a que el Ello, el Yo y el Superyó se remodelan, dando lugar a una configuración de la identidad, en términos de la representación de sí mismo y de la sexualidad. Además, se consolida lo profundo del psiquismo y de la historia que el sujeto hace de sí mismo (ibíd.).

La adolescencia tiene una connotación particular, pesarosa diría yo: se le atribuyen un montón de representaciones deficitarias asociadas con la psicopatología. De cierta manera, esto le permite a quienes les compete «desencartarse» de los adolescentes y exonerarse de la tarea de acompañarlos en el cuidado de su crecimiento. La asociación de crecimiento con sufrimiento me parece un tanto peligrosa. Me pregunto: ¿solo se crece a través del sufrimiento?, ¿a qué nos referimos cuando hablamos de sufrimiento? Estas preguntas no se traducen en que yo ponga en duda la angustia que genera el transitar por el desconocimiento y la incertidumbre de crecer. Es claro que el sufrimiento no es solo una convención social; como muestra de ello, tenemos el cuerpo propio.

Para volver a la pregunta sobre qué necesita un joven para permitirse ser y estar en un espacio como el clínico, recreemos primero la escena de un sujeto que entra por primera vez a un consultorio: el sujeto entra, ve dos o tres sillas, un escritorio con algunas hojas encima, posiblemente una caja de pañuelos y uno que otro adorno; no sabe muy bien dónde sentarse, así que improvisa o pregunta dónde puede hacerlo. Desde mi lugar, es como ver a un sujeto entrar en una dimensión extraña. Sabe de ese espacio lo que ha escuchado de él o de 
experiencias similares previas; así que de entrada es un lugar que el sujeto siente como ajeno, como que no le pertenece, tierra de otro.

En ese orden de ideas, lo primero que se necesita es que el sujeto pueda apropiarse del espacio. Y esto pasa de diferentes formas: a medida que el sujeto visita ese espacio, es decir, por el tiempo que el sujeto permanece ahí, o porque el psicólogo procura mencionar algo así como que "en este espacio puede decir lo que se le ocurra, este es su espacio». Entonces, empezamos a ver a un sujeto que sube las piernas en la silla o deposita su maleta y se ve más suelto; acomoda el lugar al sentarse o realiza algún tipo de expresión corporal o verbal que le comunica al psicólogo que empieza a permitirse estar con su propia humanidad.

Los jóvenes consultantes llegan temerosos. Pareciera que el síntoma relacional contemporáneo es la desconfianza. En este sentido, otra de las necesidades a las que me he visto enfrentada es la de saber cómo ofrecer una experiencia que le permita al paciente sentir que puede hablar, que no será condenado por lo que dice o por lo que su cuerpo expresa, que lo que va a decir no es una «bobada» o una injuria merecedora de un lugar en el Infierno, o que va a ser lastimado. Ese es finalmente uno de los miedos más profundos: el de ser lastimado; al cual se le suma el temor de ser avergonzado, rechazado o abandonado.

En algún momento del proceso los pacientes ponen a prueba la posibilidad de confiar o no en el psicólogo. Si se logra «pasar» esta prueba, es posible que el contenido de las sesiones tome un sentido particular y especialmente íntimo. Es por esto que el dispositivo clínico en el contexto universitario hace las veces de espacio transicional, que les permite a los jóvenes tramitar la angustia de estar solos, hacer amigos, crecer, ser en un espacio diferente a los conocidos, responder a las exigencias académicas y sociales y consolidar su vida sexual, entre otros aspectos que permiten asumir el estatus de universitario. Winnicott (196ob) intenta descifrar la función de ponerse a prueba los jóvenes. Según sus palabras,

... Ello parece deberse sobre todo a que experimentan sentimientos intensos y atemorizantemente nuevos, y quieren estar seguros de que los controles externos no han desaparecido. Pero, al mismo tiempo, deben demostrarse que pueden liberarse de esos controles y afirmarse como individuos.

En el dispositivo clínico hay dos protagonistas, dos agentes. He mencionado al paciente, ahora hablaré del psicólogo, como cuidador del crecimiento de sus pacientes. Escogí la imagen de cuidador, a causa de que el crecimiento, pensándolo en términos de transición, no se va a detener por la ausencia de este agente en la realidad del paciente. Se me dificulta pensar que un paciente ingresa a un consultorio sin una demanda o por azares del destino, como si fuese gratuito estar encerrado entre cuatro paredes con un extraño que lo ve, le 
pregunta sobre sí mismo y lo escucha. En esa medida, su demanda es una invitación a ser parte de algo, diría yo, de una relación.

Ricardo Rodulfo (2012: 57-70) ya había pensado algunas indicaciones sobre el cuidado de la experiencia en el dispositivo clínico. En sus palabras (ibíd.: 58):

... tener cuidado, tomarse el cuidado de cuidar, implica asumir una función tan esencial como ajena a toda pretensión de ser-causa en la existencia del otro; cuidar la posibilidad de que tenga lugar una experiencia es absolutamente distinto a arrogarse la potencia de la omnipotencia: causarle una experiencia al otro.

Vale resaltar que el cuidar no es una actitud totalmente complaciente. Para mí personalmente, el cuidado significa una actitud de negociación, receptividad, comprensión, desnudez y, si se quiere o se permite, espontaneidad. Rodulfo (ibíd.: 57-70) propone los conceptos winnicottianos de holding, juego y creatividad como artificios técnicos para cuidar una experiencia. El holding (en algunos momentos el handling) se posiciona como una forma de cuidar. Winnicott (1960a) lo define como una de las funciones maternantes que se da cuando la madre es capaz de identificarse con su bebé. Ahora bien, el holding se da de muchas formas: puede ser la mirada, un acto de sostenimiento, un corte, un direccionamiento o una interpretación. Como decía Winnicott (1954), «siempre que comprendemos profundamente a un paciente y que se lo demostramos por medio de una interpretación correcta y oportuna, de hecho lo que estamos haciendo es sostenerle y participar en una relación...».

El juego, por su parte, es definido como una actividad universal que posibilita el crecimiento; al igual, se presenta como una vía de comunicación en psicoterapia, posicionando esta última como una manera muy particular de juego, a favor de la comunicación consigo mismo y con los otros (Winnicott, 1972: 65). Paralelamente, la creatividad es «la conservación durante toda la vida de algo que en rigor pertenece a la experiencia infantil: la capacidad de crear el mundo» (Winnicott, 1970: párr. 7). El sujeto creativo, en cualquier escenario está jugando, lo que no implica que la actividad creativa sea ajena a las preocupaciones; es más, se valen la agresión, la angustia y la culpabilidad. De ahí que la tendencia de autodestrucción no solo fragmenta sino que contribuye a la estructuración del psiquismo (McDougall, 2005: 87).

En el dispositivo clínico, darle lugar a la creatividad es permitir que se conserve algo íntimo, tal vez enigmático, y crear a partir de allí una noción de quién se es, a quién se ama y qué hacer en determinadas situaciones que generan preguntas al sujeto, al joven que consulta, que necesita un espacio y una relación con otro que soporte su angustia de crearse. Es por esto que en el dispositivo clínico deben permitirse los «actos de libertad y humanidad», como los nombra Jordan (2016). En este espacio y en esta relación se asumen riesgos, se realizan actos de fe, se encarna la incertidumbre; ambos agentes se hacen a una comprensión, que 
determina su modo de ser en dicho espacio, lo cual se escenifica en «la vulnerabilidad compartida con nuestros pacientes» (Jordan, 2016: 786).

En resumidas cuentas, el psicólogo, en el dispositivo clínico, puede valerse de su destreza para cuidar una experiencia en la cual el joven se está preguntando, la cual seguramente tiene un lugar fundamental en su psiquismo y en su realidad. Por ende, se está proporcionando un espacio que facilita al joven elaborar su angustia, crear una historia de sí y de los otros, al igual que hacerse a una forma de estar en el mundo. Ser cuidador en este espacio representa una forma de hacer de la clínica psicológica con jóvenes universitarios un ejercicio ético.

\section{REFERENCIAS}

Congreso de Colombia (2013): Ley Estatutaria n. ${ }^{\circ} 1622$ (Estatuto de Ciudadanía Juvenil); 29 de abril, 2013. Recuperado de:

http://wsp.presidencia.gov.co/Normativa/Leyes/Documents/2013/LEY\%201622\%20DEL\%202 9\%20DE\%20ABRIL\%20DE\%202013.pdf

Espinosa, H. D. (2010): «Las tareas de la adolescencia: una lectura de la adolescencia normal». Clínica e Investigación Relacional. Revista Electrónica de Psicoterapia, 4 (3), oct., pp. 620-47. Recuperado de:

http://www.psicoterapiarelacional.es/portals/o/ejournalceir/v4n3_2010/08 hdespinosa_tareas-adolescencia_ceir $v_{4} n 3$.pdf

Ferenczi, S. (2008): Sin simpatía no hay curación. Diario clínico de 1932. Buenos Aires: Amorrortu (2. ${ }^{\mathrm{a}}$ ed.).

Jordán, J. F. (2016): «Siendo-con. Desnudez, comprensión, conocimiento y transformación en la relación terapéutica». Clínica e Investigación Relacional. Revista Electrónica de Psicoterapia, 10 (3), oct., pp. 780-92. Recuperado de:

http://www.psicoterapiarelacional.com/Portals/o/eJournalCelR/V10N3_2016/13_Jordan_2016 Siendo-con_CelR_V10N3.pdf

McDougall, J. (2005): Las mil y una caras de Eros: la sexualidad humana en busca de soluciones. Trad. de J. Piatigorsky. Buenos Aires: Paidós. 1. ${ }^{\text {a }}$ ed. en ing.: 1908.

Rodulfo, R. (2012). Padres e hijos: en tiempos de la retirada de las oposiciones. Buenos Aires: Paidós.

Winnicott, D. W. (1954): «Replegamiento y regresión». En: PsicoMundo. La Red Psi en Internet (dir.: M. Sauval). Recuperado de: http://www.psicoanalisis.org/winnicott/replregr.htm

(1960a): «La pareja madre-lactante». En: PsicoMundo. La Red Psi en Internet (dir.: M.

Sauval). Recuperado de: http://www.psicoanalisis.org/winnicott/lapamala.htm

(196ob): «Sobre la seguridad». En: PsicoMundo. La Red Psi en Internet (dir.: M. Sauval).

Recuperado de: http://www.psicoanalisis.org/winnicott/sobrelas.htm 
(1970): «Vivir creativamente». En: PsicoMundo. La Red Psi en Internet (dir.: M. Sauval). Recuperado de: http://psicoanalisis.org/winnicott/vivimte.htm

(1972): Realidad y juego. Buenos Aires: Gedisa.

Original recibido con fecha: 6/12/2017 Revisado: 30/03/2018 Aceptado: 30/05/2018 